\title{
Steven Raikin: Foot and ankle surgery: tricks of the trade
}

\section{Thieme Verlag, New York, Stuttgart, Delhi, Rio de Janeiro, 2018, 437 pp, 457 figs., Hardcover, EUR (D) 164,99, EUR (A) 169,70, CHF 190,00, ISBN: 978-1-62623-491-8}

\author{
Alain G. Graftiaux ${ }^{1} \cdot$ Pierre H. Kehr ${ }^{1}$
}

Received: 18 June 2019 / Accepted: 20 July 2019 / Published online: 25 July 2019

(c) Springer-Verlag France SAS, part of Springer Nature 2019

This multi-authored book, mainly American but also European, Chinese and South African, is above all a practical book for all surgeons who want clear information and easy access to a surgical technique.

Each chapter is constructed in the same way: with the indications and the preoperative assessment, the purpose of the operation but also the other possible treatments. The technique is described step by step, richly illustrated and supplemented by tricks and traps as well as postoperative care. A short list of references will allow the surgeon to know more.

All parts of the foot and ankle are treated whether it is traumatic or degenerative bone pathology, ligament or nerve. The choice of techniques is broad and includes arthroscopic and prosthetic techniques.
This book will not allow to deepen a subject, but its practical side will be very useful to search for information or perfect its operative gesture.

\section{Compliance with ethical standards}

Conflict of interest The authors declare that they have no competing interests.

Publisher's Note Springer Nature remains neutral with regard to jurisdictional claims in published maps and institutional affiliations.
Pierre H. Kehr

pierre.kehr@gmail.com

1 Strasbourg, France 